Population genetics

\section{Eel mystery: time makes a difference}

\section{A Vasemägi}

Heredity (2009) 103, 3-4; doi:10.1038/hdy.2009.38; published online 15 April 2009

$\mathrm{P}$ opulation genetic studies that report seemingly negative results, such as lack of significant differences, rarely end up in the headlines of leading scientific journals. The work by Palm et al. (2009), however, does exactly this by using a comprehensive temporal data set to show that, despite several recent claims, the European eel (Anguilla anguilla) can still be considered as a single, spatially homogeneous population.

The life cycle of the European eels has been subject to speculation for centuries and various hypotheses have been put forward to explain the apparent lack of fully mature adults and juveniles along the European coast. Aristotle claimed that eels emerge spontaneously after the rain, whereas Pliny the Elder suggested that adult eels rub their skin against rocks and the pieces that come off subsequently metamorphose into young eels (Aristotle, 1910; Pliny the Elder, 1855). Furthermore, just over a 100 years ago eel larvae were considered as a separate species, named Leptocephalus brevirostris Kaup, 1856. The first discovery of small eel larvae in the middle of the Atlantic Ocean followed by the analyses of their size distribution at the beginning of the twentieth century finally revealed that the spawning area of the European eel is in the Sargasso Sea, more than $4000 \mathrm{~km}$ away from the closest freshwater feeding grounds in Europe (Hjort, 1910; Schmidt, 1923). Since then, the European eel has often been used as a textbook example of a single randomly mating or panmictic population. This is because the maintenance of spatial genetic structure would only be possible if there is spatial or temporal separation during the reproduction of adult eels that originate from different locations in Europe, as well as accurate homing of larvae to their parents' freshwater feeding areas.

Early genetic studies using various molecular markers did not challenge the widely accepted panmixia hypothesis (see review by Maes and Volckaert, 2007), but, more recently, three studies based on microsatellite markers have reported weak but significant popula- tion differentiation and isolation by distance patterns in the European eels (Daemen et al., 2001; Wirth and Bernatchez, 2001; Maes and Volckaert, 2002). One of the important limitations of these studies, however, has been the lack of temporal replicates and the use of samples containing eels from different year-classes (cohorts). It has subsequently been suggested that if samples from different locations contain different cohorts, this may produce spurious signatures of spatial population structuring as a result of temporal heterogeneity (Dannewitz et al., 2005).

Using a temporal data set consisting of maturing silver eels of known age collected over decades, Palm et al. (2009) were not able to identify any signs of spatial genetic differentiation between geographically distant samples collected from Southern and Northern Europe. In addition, they did not detect any significant temporal variation between cohorts, even though there was a slight tendency towards a positive correlation between temporal and genetic distances similar to that found by Maes et al. (2006). It is important to keep in mind that Palm et al. (2009) employed rather limited numbers of microsatellite markers in their analyses (four or six loci, depending on the analyses), but nevertheless, their power analyses indicate that the true level of genetic differentiation between Mediterranean and Baltic/North Sea samples must be extremely small $\left(\mathrm{F}_{\mathrm{ST}}<0.0004\right)$ to remain undetected. Clearly, by using larger numbers of loci it would be possible to detect even lower levels of divergence, if present. On the basis of these findings, the most plausible explanation for the seemingly conflicting results in European eels probably stem from the finite population size that can cause small but significant differences between samples of different age. When such temporal variation is taken into account, the work by Palm et al. (2009) together with the earlier study of Dannewitz et al. (2005) suggests that European eels can still be considered a panmictic species. Both of these studies highlight the importance of temporal replication when testing for spatial population structure and suggest that the role of temporal genetic heterogeneity has been underestimated as a potential confounding factor when assessing subtle population structures in marine organisms.

Ultimately, the question on the presence or absence of panmixia in the European eel is not only of theoretical importance. On the contrary, it is very much an acute conservation issue as the development of a biologically sound and efficient conservation and management plan for European eels crucially depends on understanding the population structure of this drastically declining species. The recruitment of European eels is currently only 1-5\% compared with what it was in the 1970s, and it has been added to the IUCN Red List of Threatened Species as critically endangered (Freyhof and Kottelat 2008). The causes of this sharp decrease are still unclear and several hypotheses have been proposed, including overfishing, introduced parasites (nematode Anguillicola crassus), construction of dams, predators (particularly cormorants), North Atlantic oscillation, PCB pollution and climate change.

We now know much more about the biology of European eels than the early naturalists of ancient Greece, but without a doubt, there are still many exciting discoveries ahead, as no one, in fact, has observed the spawning and eggs of European eels in the Sargasso Sea. If the current drastic decrease in abundance continues, however, the species might go extinct before we are fully able to understand the enigmatic life cycle of the European eel.

$\operatorname{Dr}$ A Vasemägi is at the Department of Biology (Vesilinnantie 5), University of Turku, Turku 20014, Finland and at the Department of Aquaculture, Institute of Veterinary Medicine and Animal Science, Estonian University of Life Sciences, Tartu 51014, Estonia.

e-mail: anti.vasemagi@utu.fi

Aristotle (1910). The History of Animals. Book VI. Clarendon Press: Oxford.

Daemen E, Cross T, Ollevier F, Volckaert FAM (2001). Analysis of the genetic structure of European eel (Anguilla anguilla) using microsatellite DNA and mtDNA markers. Mar Biol 139: 755-764.

Dannewitz J, Maes GE, Johansson L, Wickström H, Volckaert FAM, Järvi T (2005). Panmixia in the European eel: a matter of time.... Proc $R$ Soc B 272: 1129-1137.

Freyhof J, Kottelat M (2008). IUCN Red List of Threatened Species.

Hjort (1910). The 'Michael Sars' North Atlantic Deep-Sea Expedition, 1910. Nature 85: 52-55.

Maes GE, Volckaert FAM (2002). Clinal genetic variation and isolation by distance in the European eel Anguilla anguilla. Biol J Linn Soc 77: 509-521.

Maes GE, Pujolar JM, Hellemans B, Volckaert FAM (2006). Evidence for isolation by time in 
the European eel (Anguilla anguilla L.). Mol Ecol 15: 2095-2107.

Maes GE, Volckaert FAM (2007). Challenges for genetic research in European eel management. ICES J Mar Sci 64: 1463-1471.

Palm S et al. (2009). Panmixia in European eel revisited: no genetic difference between maturing adults from southern and northern Europe. Heredity 103: 82-89.

Pliny the Elder (1855). The Natural History. Book IX. Taylor and Francis: London.
Schmidt J (1923). The breeding places of the eel. Phil Trans R Soc Lond B 211: 179-208.

Wirth T, Bernatchez L (2001). Genetic evidence against panmixia in the European eel. Nature 409: $1037-1040$

\section{Editor's suggested reading}

Chevolot M, Ellis JR, Rijnsdorp AD, Stam WT, Olsen JL (2008). Temporal changes in allele frequencies but stable genetic diversity over the past 40 years in the Irish Sea population of thornback ray, Raja clavata. Heredity 101: 120-126.

Fauvelot C, Lemaire C, Planes S, Bonhomme F (2007). Inferring gene flow in coral reef fishes from different molecular markers: which loci to trust? Heredity 99: 331-339.

Lin J, Quinn TP, Hilborn R, Hauser L (2008). Fine-scale differentiation between sockeye salmon ecotypes and the effect of phenotype on straying. Heredity 101: 341-350. 